\title{
Recent advances in the study of avian malaria: an overview with an emphasis on the distribution of Plasmodium spp in Brazil
}

\author{
Érika Martins Braga1/++, Patricia Silveira1', Nayara Oliveira Belo', Gediminas Valkiūnas² \\ 'Departamento de Parasitologia, Instituto de Ciências Biológicas, Universidade Federal de Minas Gerais, \\ Av. Antônio Carlos 6627, 31270-901 Belo Horizonte, MG, Brasil ${ }^{2}$ Nature Research Centre, Akademijos 2, Vilnius 21, LT-08412, Lithuania
}

Avian malaria parasites (Plasmodium) have a worldwide distribution except for Antarctica. They are transmitted exclusively by mosquito vectors (Diptera: Culicidae) and are of particular interest to health care research due to their phylogenetic relationship with human plasmodia and their ability to cause avian malaria, which is frequently lethal in non-adapted avian hosts. However, different features of avian Plasmodium spp, including their taxonomy and aspects of their life-history traits, need to be examined in more detail. Over the last 10 years, ecologists, evolutionary biologists and wildlife researchers have recognized the importance of studying avian malaria parasites and other related haemosporidians, which are the largest group of the order Haemosporida by number of species. These studies have included understanding the ecological, behavioral and evolutionary aspects that arise in this wildlife host-parasite system. Molecular tools have provided new and exiting opportunities for such research. This review discusses several emerging topics related to the current research of avian Plasmodium spp and some related avian haemosporidians. We also summarize some important discoveries in this field and emphasize the value of using both polymerase chain reaction-based and microscopy-based methods in parallel for wildlife studies. We will focus on the genus Plasmodium, with an emphasis on the distribution and pathogenicity of these parasites in wild birds in Brazil.

Key words: Plasmodium - avian malaria - birds - conservation - experimental infection

Haemosporidian parasites (Sporozoa: Haemosporida) are a cosmopolitan group of obligate heteroxenous protists that parasitize amphibians, reptiles, birds and mammals and utilize blood-sucking dipteran insects (Insecta: Diptera) as vectors. Haemosporidians have been studied since 1884 and are considered to be important models in the study of human malaria (Lucena 1939, Garnham 1966). Malaria, one of the most well-known haemosporidioses, is considered to be a particularly important parasitic disease in tropical and subtropical countries, infecting and killing several million people each year (Snow \& Omumbo 2006). Early studies on avian Plasmodium spp have made invaluable contributions to basic research in human malariology. The discovery of rodent malaria parasites and the development of continuous in vitro cultivation techniques for the most deleterious human malaria species, Plasmodium falciparum, decreased the scientific focus on avian Plasmodium spp at the end of the XX century (Valkiūnas 2005). However, the extensive understanding gained from pioneering studies of avian haemosporidians and their significance in evolutionary and conservation biology (Bensch et al. 2009, Ricklefs \& Outlaw 2010) have helped reestablish the field. Currently, these parasites are being used extensively for ecological and evolutionary modelling studies of host-parasite

Financial support: CNPq, FAPEMIG, UFMG

+ Corresponding author: embraga@icb.ufmg.com.br

Received 19 March 2011

Accepted 7 June 2011 systems, which studies are essential for understanding ecological parasitology and vertebrate conservation and management (van Riper III et al. 1994, Møller \& Nielsen 2007, Marzal et al. 2008, Bonneaud et al. 2009, Levin et al. 2009, Loiseau et al. 2010, Sehgal et al. 2011).

Taxonomists have described more than 200 species of avian haemosporidians from hundreds of bird species and have placed them into four distinct genera, Plasmodium, Haemoproteus, Leucocytozoon and Fallisia. The vectors for these parasites are exclusively blood-sucking dipteran insects belonging to 17 genera (Valkiūnas 2005, Njabo et al. 2011). The features that have been traditionally used to define genera and subgenera of haemosporidian parasites include the morphology of blood, tissue and vector stages when analyzed under a light microscope, vector preference, the ability to digest hemoglobin when parasitizing red blood cells, the course and details of the life-cycle (Garnham 1966, Laird 1998, Valkiūnas 2005). Species of avian haemosporidian parasites have traditionally been described based on the morphology of their blood stages and limited experimental information on their vertebrate host specificity. Their identification based on microscopic observation is based mainly on characteristics of the asexual and sexual intracellular blood stages, morphometric analyses, such as length, width, area, number and size of pigment granules (Garnham 1966, Valkiūnas 2005, Martinsen et al. 2006). Importantly, blood films, which are used for microscopic examinations, should be well-prepared and should be examined properly by skilled investigators (Valkiūnas et al. 2008a). Recent molecular studies using gene sequence analysis have supported the classification of the majority of genera and many subgenera of avian haemosporidian parasites and have provided additional information 
about the phylogenetic relationships between currently recognized genera (Martinsen et al. 2006, Valkiūnas et al. 2009). Phylogenetic reconstruction of cytochrome $b$ (cytb) lineages from readily distinguishable morphospecies has shown that many lineages form monophyletic clusters that match morphospecies. Such congruence between genetic and morphological data demonstrates the integration of traditional parasitology and molecular biology (Perkins \& Schall 2002, Križanauskiené et al. 2006, 2010, Hellgren et al. 2007, Palinauskas et al. 2007). However, molecular studies based on both mitochondrial and nuclear DNA have also shown that some morphological and life-history traits within haemosporidian parasites do not necessarily indicate evolutionary coherence (Perkins \& Schall 2002, Bensch et al. 2004, Ricklefs et al. 2004), which warrants further investigation.

Species of avian Plasmodium: difficulties with diagnosis - The term "malaria parasite" was historically used to name haemosporidian species that undergo asexual reproduction in vertebrate blood, hence the name Plasmodium spp (Garnham 1966, Coatney et al. 1971, Valkiūnas 2005). It is important to note that species of Plasmodium complete merogony in erythrocytes, while Haemoproteus spp do not. Additionally, avian and mammalian Plasmodium spp are transmitted by and complete sporogony exclusively in mosquitoes (Culicidae), while Haemoproteus spp do not. The main diagnostic differences between these haemosporidians have been previously summarized (Garnham 1966, Valkiūnas 2005). However, some disease symptoms caused by both Plasmodium and Haemoproteus species, such as hemozoin deposition and anaemia, are similar (Chen et al. 2001, Schrenzel et al. 2003), and both genera include species that cause substantial morbidity and mortality in natural populations. Importantly, recent molecular analyses show that the genus Plasmodium is monophyletic with respect to Haemoproteus (Martinsen et al. 2008), suggesting that the old name "malaria" should be restricted to disease caused by Plasmodium species (Valkiūnas et al. 2005). Disease caused by Haemoproteus parasites has traditionally been termed hemoproteosis. Therefore, this review will mainly consider malaria parasites of the genus Plasmodium.

Avian malaria parasites are transmitted by numerous species of mosquitoes; the majority of parasites investigated use species of the genera Culex, Aedes, $\mathrm{Cu}$ liseta, Anopheles, Mansonia and Aedeomya as vectors (Valkiūnas 2005). Recently, Njabo et al. (2011) showed that Coquillettidia species might be important vectors for avian malaria in African birds, indicating that our understanding of avian malaria vectors is incomplete, particularly in tropical regions.

Sexual reproduction of Plasmodium species occurs in the mosquitoes, indicating that the vectors are definitive hosts. Although general patterns of avian malaria parasite epizootiology have been studied (Garnham 1966, Atkinson et al. 1995, McConkey et al. 1996), little is still known about the vectors for many avian Plasmodium species or the diversity of parasites that certain vectors might transmit. The interactions between malaria parasites and their vectors are complex and can be affected by both genetic and environmental factors (Tripet et al.
2008). Recently, several studies have used molecular markers to examine the distribution of avian malaria parasite lineages in wild-caught vectors (Gager et al. 2008, Istiaq et al. 2008, Ejiri et al. 2009, Kim et al. 2009, Kim \& Tsuda 2010, Kimura et al. 2010). However, the "parasitevector-vertebrate host" interactions remain understudied for avian malaria, particularly in tropical countries.

Five subgenera of avian malaria parasites traditionally are accepted as valid: Haemamoeba (Grassi \& Feletti 1890), Giovannolaia, Novyella and Huffia (Corradetti, Garnham \& Laird 1963) and Bennettinia (Valkiūnas 1997). Classification of avian malaria parasites into subgenera facilitates species identification when using optical microscopy to perform morphological analysis in blood films. The validity of some subgenera of avian Plasmodium remains unclear based on limited molecular analysis (Martinsen et al. 2006) and some recently established subgenera (Landau et al. 2010) also need to be validated. Clearly more genetic analysis is needed before the subgeneric classification of these parasites can be reconstructed (Palinauskas et al. 2007, Valkiūnas et al. 2009).

Species identification of avian haemosporidian parasites is a complex task, mainly because most wild birds have low levels of parasitaemia and are frequently coinfected with haemosporidians belonging to the same or different genera. These are the most common obstacles to Plasmodium spp identification, particularly for the non-experts. However, the current lack of taxonomic experts and training in Plasmodium taxonomy is a larger issue. Many species of avian malaria parasites are very distinct and some of them can be identified based on single cells in blood films. For instance, the presence of markedly vacuolated trophozoites or lobulated gametocytes clearly indicates infection with Plasmodium teje$\mathrm{rai}$, a parasite whose transmission seems to be restricted to South America (Galbadon \& Ulloa 1977). There is an urgent need to train taxonomists to identify malaria parasites because few experts have the knowledge base to identify avian Plasmodium spp and few people in the next generation of scientists are learning these taxonomic skills (Valkiūnas et al. 2008a).

Because primary acute haemosporidian infections are particularly pathogenic (Atkinson et al. 1995, Palinauskas et al. 2011), many infected birds are thought to be undersampled in field studies that use mist-net capture methods or some other traditional ornithological bird capture methods (Valkiūnas 2005). Hence, captured infected birds are generally at the chronic (relatively benign) stage of infection with low levels of parasitaemia in blood smears. The minimal visualization of parasites in blood smears can lead to an underestimated diagnosis, particularly in studies related to the prevalence of parasites in bird populations (Ribeiro et al. 2005, Garamszegi 2010). Furthermore, to identify the Plasmodium species with greater certainty, all the main blood stages of the parasite (trophozoites, meronts and gametocytes) should be examined, preferably using samples with a relatively intensive parasitaemia (approximately over 0.1\%) (Valkiūnas 2005).

Another factor that markedly hampers species identification is variability in the specificity of avian Plasmodium spp, i.e. the same species of Plasmodium can 
develop in birds belonging to several families and even orders, but some species seem to be relatively host restricted (Iezhova et al. 2005, Križanauskiené et al. 2006, Palinauskas et al. 2009, 2011, Loiseau et al. 2010). For example, the lineage P-SGS1 of Plasmodium relictum is a generalist and has been found in over 40 species of birds belonging to several families of the order Passeriformes. Palinauskas et al. (2008) have experimentally demonstrated that there are marked differences in the susceptibility of five different species of passeriform birds to this parasite. In this study, one host species (starling Sturnus vulgaris, Sturnidae) was completely resistant and a few house sparrow (Passer domesticus, Passeridae) individuals were susceptible. However, all individuals from three other bird species (Loxia curvirostra, Spinus spinus, Fringilla coelebs, Fringillidae) were easily infected, demonstrating that susceptibility to the same parasite varies markedly between bird species and among individuals of the same species. Conversely, some Plasmodium lineages have been reported only in several species of sunbirds in Africa (Loiseau et al. 2010). Hence, the available data shows that the majority of malaria parasite species have a broad range of avian hosts, but there are also exceptions (Beadell et al. 2006). These observations should be considered during ecological and evolutionary biology studies. To circumvent the main limitations on microscopic detection, molecular diagnostics of haemosporidians have been used, improving both the identification of parasites and the detection of parasitaemia (Bensch et al. 2000, Perkins \& Schall 2002, Waldenström et al. 2004). Notably, both polymerase chain reaction (PCR)-based and microscopy-based techniques have limitations in diagnosing malaria parasites (Valkiūnas et al. 2006, 2008b). Molecular methods that use the PCR-based techniques to amplify specific regions of the Plasmodium spp genome have proved to be more sensitive in the diagnosing avian malaria when there are low levels of parasitaemia (Richard et al. 2002, Waldenström et al. 2004). However, the PCRbased techniques that are currently used frequently do not identify co-infections with haemosporidian parasites that belong to the same and different genera (Valkiūnas et al. 2006, Martínez et al. 2009). Additional limitations of PCR-based techniques have been extensively discussed (Pérez-Tris et al. 2005, Ribeiro et al. 2005, Valkiūnas et al. 2008b, Martínez et al. 2009). Notably, professional examination of blood films shows similar trends in the prevalence of haemosporidian parasites as PCR-based diagnostics (Valkiūnas et al. 2008a). The lack of sensitivity of microscopy in diagnosing malaria is not as dramatic as some authors describe (Richard et al. 2002) when good skilled investigators examine highquality blood films. Currently, the parallel application of PCR-based and microscopy-based techniques appears to be effective in wildlife malaria studies (Valkiūnas et al. 2008b, 2011, Garamszegi 2010).

An interesting feature of malaria parasites is that they multiply in peripheral blood, facilitating experimental infections via subinoculation of infected blood into susceptible hosts. High levels of parasitaemia develop during such primary infections, during which all the stages necessary for parasite species identification are available (Palinauskas et al. 2007). This procedure can be used in Plasmodium taxonomic studies and constitutes an easy technique to determine the subgenus and species of malaria parasites with greater confidence, which is particularly important during the description of new Plasmodium species and the development of parasite molecular diagnostics. The increase of parasitaemia also allows for reliable morphometry and statistical analyses of blood stages, which can then be compared to data available for other parasites in museum collections (Garnham 1966, Valkiūnas 2005). Currently, the education of a new generation of taxonomists with good knowledge base of both parasite morphology and molecular biology is essential in improving the identification of Plasmodium species in wildlife. The formation of research groups that combine different expertise in molecular parasitology and taxonomy of avian Plasmodium is urgently needed (Valkiūnas et al. 2011).

Emerging difficulties in molecular analysis of malaria parasites - Currently, few molecular markers are widely used in the molecular analysis of avian haemosporidians (Martinsen et al. 2008). Mitochondrial genome markers are commonly used in phylogeny and genetic diversity studies of avian malaria parasites (Hellgren et al. 2004, Waldenström et al. 2004, Martinsen et al. 2008, Bensch et al. 2009). Importantly, the studies based on mitochondrial genome markers provide good congruence with fundamental data from traditional parasitology. Recently, Martinsen et al. (2008) published the first large phylogeny of Plasmodium spp and related haemosporidian parasites, which was generated using sequence data from four genes found on the parasites' three genomes - two mitochondrial genes: $c y t b$ and cytochrome oxidase I, one nuclear gene (adenylosuccinatelyase) and one plastid gene (caseinolytic protease). Using both Bayesian and maximum parsimony analyses, the authors concluded that the genus Plasmodium is paraphyletic with respect to Hepatocystis, a group of species with a different life cycle and morphology, and that Plasmodium of birds and squamate reptiles all fall within a single clade, with evidence for repeated switching between birds and squamate hosts (Martinsen et al. 2008). Thus, the monophyletic origin of Plasmodium in respect to avian Haemoproteus spp has been shown.

Notably, several studies based on molecular analysis of the malaria parasite and related haemosporidians have revealed a wealth of genetic diversity among their lineages (Bensch et al. 2000, Ricklefs \& Fallon 2002). DNA sequences from numerous parasite species have been deposited in GenBank, which has become an invaluable resource for the study of different biological aspects of these parasites. However, the majority of DNA sequences in GenBank have only been identified to the genus level and sometimes at even higher levels of classification. The low number of named haemosporidian species available in GenBank has hindered the process of linking information from DNA sequences to more traditional parasitology-based morphological species identifications. The lack of such linkages has impeded the incorporation of the huge knowledge base from traditional parasitology into 
the rapidly developing field of molecular biology. Additionally, the misidentification of parasites in GenBank has been a particular concern of researchers (Valkiūnas et al. 2008a). The correct linkage of traditional parasitology data with sequence information is increasingly important because molecular approaches are revealing vastly more parasite diversity than had been previously known, which emphasizes the crucial need for traditional biological analyses to confirm the real significance of these molecular observations. Therefore, the combination of traditional parasitology and molecular biology analyses has become an essential part of recent wildlife malariology studies (Valkiūnas et al. 2011).

Studies on the prevalence and genetic diversity of malaria parasites in Brazil - Parasites reduce the fitness of their hosts and can constitute a strong selective force operating within natural populations (Lefèvre et al. 2008). Brazil has a particularly high level of diversity and species richness in its ornithological fauna compared to other countries. In the Brazilian forests, some species of birds are considered a priority for conservation because of their high degree of endemism or their risk of extinction.

Although Brazil confronts serious problems in conserving its biomes and biodiversity, few studies have been conducted to assess the diversity of haemosporidians and other blood parasites in different species of wild birds (captive or free living) or the influence of parasitism in altered and intact environments (Bennett \& Lopes 1980, Woodworth-Lynas et al. 1989, Ribeiro et al. 2005, Fecchio et al. 2007, Belo et al. 2009, 2011, Bueno et al. 2010, Lima et al. 2010, Sebaio et al. 2010, Fecchio et al. 2011) (Table).

Two pioneering studies have examined the prevalence of haemoparasites in a large number of birds in the state of São Paulo (SP), Brazil (Bennett \& Lopes 1980, Woodworth-Lynas et al. 1989). These studies represent the first prominent surveys conducted in Brazil that assess the prevalence of haemoparasites in wild birds from various families while comparing the parasitism among birds captured at different locations. In these studies, only microscopy-based methods were used to provide an original and recognized database.

Bennett and Lopes (1980) have reported the seasonal distribution, host distribution and prevalence of parasitism in approximately 3,500 birds from three areas in SP, Brazil [Itapetininga $\left(23^{\circ} 40^{\prime} \mathrm{S} 48^{\circ} 05^{\prime} \mathrm{W}\right)$, Casa Grande $\left(23^{\circ} 40^{\prime} \mathrm{S} 45^{\circ} 55^{\prime} \mathrm{W}\right)$ and Guaratuba $\left.\left(23^{\circ} 45^{\prime} \mathrm{S} 45^{\circ} 55^{\prime} \mathrm{W}\right)\right]$, which showed a low overall prevalence of Plasmodium $(0.9 \%)$. Of the three areas evaluated, one region (Guaratuba) showed a significantly higher prevalence of haemoparasites (Plasmodium, Haemoproteus, Trypanosoma, Leucocytozoon, microfilaria) while a different region (Itapetininga) showed a higher prevalence of Plasmodium (1.8\%). These results may be explained by the differences in the environment and the composition of the avifauna investigated in each area.

To investigate whether the differences in the prevalence of haemoparasites could be influenced by the distribution of bird species, Woodworth-Lynas et al. (1989) greatly expanded upon the previous sample size. In that survey, 15,574 birds from nine localities in SP, Brazil were examined (Itapetininga, Casa Grande, Guaratuba, Iguapé, Zoológica, Registro, Peruíbe, Itanhaém and Piedade). The same three areas previously analyzed by Bennett and Lopes (1980) were also included and considered in the study (Itapetininga, Casa Grande and Guaratuba). The overall prevalence of Plasmodium was low $(0.6 \%)$, similar to the previous report (Bennett \& Lopes 1980). Among the three areas evaluated, the Guaratuba region still showed a significantly higher prevalence of haemoparasite infection and the Itapetininga region

TABLE

Prevalence of blood parasites in wild birds from Brazil ${ }^{a}$

\begin{tabular}{lcccccc}
\hline \multirow{2}{*}{ State/biome } & Diagnosis & Examined & $\begin{array}{c}\text { Prevalence } \\
(\%)\end{array}$ & $\begin{array}{c}\text { P } \\
(\%)\end{array}$ & $\begin{array}{c}\mathrm{H} \\
(\%)\end{array}$ & References \\
\hline São Paulo & $\mathrm{M}$ & 3,449 & 7.8 & 0.9 & 3.3 & $\begin{array}{c}\text { Bennett and Lopes (1980) } \\
\end{array}$ \\
& $\mathrm{M}$ & 15,574 & 8 & 0.6 & 3.2 & Woodworth-Lynas et al. (1989) \\
& M and PCR & $3^{b}$ & 100 & 100 & - & Bueno et al. (2010) \\
Different regions & M and PCR & 119 & 18.48 & 0 & 100 & Lima et al. (2010) \\
Minas Gerais/Atlantic rain forest & M and PCR & 275 & 39.6 & 39.6 & 0 & Ribeiro et al. (2005) \\
& M an PCR & 127 & 36 & 36 & 0 & Belo et al. (2009) \\
& M & 925 & 15.8 & 9.2 & 3.2 & Sebaio et al. (2010) \\
Distrito Federal/Cerrado & M & 508 & 6.9 & 1.6 & 5.3 & Fecchio et al. (2007) \\
& M & 772 & 10.7 & 3.6 & 7.1 & Fecchio et al. (2011)
\end{tabular}

$a$ : data on free living and captive birds are given; $b$ : Plasmodium relictum identified as a causative agent responsible for death in three penguins from a zoo in the municipality of São Paulo; $c$ : in this study both parasites Plasmodium and Haemoproteus were considered as a causative agent of avian malaria; H: Haemoproteus spp; M: microscopic examination; P: Plasmodium spp; PCR: polymerase chain reaction diagnostics. 
still showed the highest prevalence of Plasmodium infection (1\%). Notably, the low prevalence observed in those studies may have been influenced by the methods used in their diagnosis because the quality of some their blood films is fairly poor, which have since been deposited in the Queensland Museum, Queensland Australia (G Valkiūnas, unpublished observations). However, the reliable data from the study include the observation that the prevalence of malaria parasites significantly varied between sampling areas, corroborating the results obtained by Bennett and Lopes (1980). The differences in the species composition of birds and the susceptibility of avian hosts observed in those three major regions of SP (Itapetininga, Casa Grande and Guaratuba) have demonstrated that these factors could influence the overall prevalence data and may reflect the distribution of haemoparasites in wildlife. These two prominent studies have shown the importance of assessing the prevalence of haemoparasites in birds from different regions and the possible directions for such research.

Brazil is composed of several different types of biomes, such as Amazônia, Cerrado, Mata Attântica, Caatinga, Pantanal and Pampas. However, the prevalence of blood parasites is unknown in some of these biomes. Considering that the prevalence of haemoparasites varies according to host distribution, the next logical step would be to examine the distribution of parasites in wild birds from several different habitats at the bird population level.

The prevalence of Plasmodium spp in wild birds from the Brazilian Atlantic Rainforest and Cerrado were reported in two different studies (Sebaio et al. 2010, Fecchio et al. 2011). Relatively low overall prevalence of Plasmodium spp among different species of passerine birds $(<10 \%)$ was observed. Another survey conducted by Ribeiro et al. (2005) determined the prevalence of Plasmodium in Brazilian birds from the Atlantic rainforest by amplifying the small subunit ribosomal ribonucleic acid (18S SSU rRNA) gene. In this study, this molecular technique was more sensitive in detecting blood parasites among wild birds than microscopy $(39.6 \%$ and $16 \%$ of infection, respectively). However, the quality of the blood films used in microscopic diagnostics and microscopic protocols was not discussed but would be important to make reliable comparisons (Valkiūnas et al. 2008b). Interestingly, these molecular data revealed that birds captured in the large forest areas had a higher prevalence of infection than birds captured in the small forest areas $(51.9 \%$ and $28.5 \%$, respectively). A bird's diet was also correlated with the prevalence of Plasmodium spp. The insectivorous birds rather than granivorous, frugivorous or omnivorous birds had a higher prevalence of infection. Birds that participate in mixed-species flocks also had a higher prevalence of infection for Plasmodium spp than birds that do not participate in this group.

Considering that disturbances in the host-parasite relationship could change the route of pathogen transmission, it is important to understand how environmental and climate changes may affect this relationship (Ricklefs et al. 2004, Sehgal 2010). Thus, there is a great need for the development of studies to evaluate the impact of deforestation on the diversity and abundance of avian malaria parasites in Brazil, as has recently been performed in African forests (Bonneaud et al. 2009, Loiseau et al. 2010). Recently, we screened 676 wild birds from three different environmental regions (intact cerrado, disturbed cerrado and transition area Amazonian rainforest-cerrado) for the presence of haemosporidian parasites (Plasmodium and Haemoproteus spp) to determine whether different habitats are associated with differences in the prevalence and diversity of infection in natural populations (Belo et al. 2011). Twenty-one mitochondrial cyt $b$ lineages including 11 from Plasmodium spp and 10 from Haemoproteus spp were identified. Surprisingly, neither the prevalence nor the diversity of infection of Plasmodium spp or Haemoproteus spp differed significantly among the three habitats studied. However, 15 of the parasite lineages had not previously been detected and may be restricted to these habitats or to this region. Further PCR-based studies combined with microscopic examinations are needed to understand the distribution patterns and biodiversity of avian haemosporidian parasites in Brazil and South America.

Pathogenicity and treatment of avian malaria - The pathogenicity of malaria parasites towards birds usually differs during the acute and chronic stages of infection. The onset of clinical signs and symptoms is associated with the acute stage of infection, which can progress very rapidly. Malaria infected birds may appear lethargic, reject food and drink and show signs of pain, ruffled feathers, closed eyes and fallen heads. In more severe cases, mucosal pallor, dyspnea, anorexia, regurgitation and death may occur (Garnham 1966, Atkinson et al. 1995, Valkiūnas 2005). The chronic stage caused by avian malaria parasites is subclinical in most cases, but relapses can occur and can even lead to severe disease under stressful conditions including seasonal changes or the occurrence of concurrent infections with other disease agents (Applegate 1970, Cranfield et al. 1994, Graczyk et al. 1994, Palinauskas et al. 2011). Moreover, other variables related to the pathogenicity of different Plasmodium species should be considered, in particular the differences in virulence for different lineages and the differences in susceptibility between different species of avian hosts and even individuals within the same species.

The susceptibility of different hosts can directly influence the level of virulence. A fascinating example is the infection caused by Plasmodium juxtanucleare, a species widely distributed in tropical and subtropical countries worldwide (Valkiūnas 2005). Interestingly, it is the only Plasmodium species that naturally infects chickens in Brazil, where the prevalence can reach up to $100 \%$ in some areas (Santos-Prezoto et al. 2004). This species has been also reported in other species of Galliformes (Versiani \& Gomes 1941, Massard \& Massard 1981, Murata et al. 2008) and in penguins (Grim et al. 2003). It is clear that the virulence of this parasite depends on the strain of the parasite, which is different for different avian hosts.

Some experimental studies examining the life cycle and transmission of P. juxtanucleare are available (AlDabagh 1961, Bennett \& Warren 1966, Krettli 1972, Lourenço-de-Oliveira \& de Castro 1991, Elisei et al. 2001, Paraense 2004, Silveira et al. 2009b). Two different stud- 
ies conducted in Brazil have demonstrated that chickens develop low levels of parasitaemia and have few clinical changes when infected with P. juxtanucleare (Krettli 1972, Silveira et al. 2009a). However, the same parasite species has caused severe clinical disorders resulting in the death of several penguins in a rehabilitation centre in Africa (Grim et al. 2003). P. juxtanucleare has also been diagnosed in a white-eared pheasant (Crossoptilon crossoptilon) that exhibited serious clinical signs, such as lethargy and pulmonary oedema, in a zoo in Japan (Murata et al. 2008). It is possible that the differences observed in the pathogenicity of $P$. juxtanucleare are due to differences in virulence between parasite lineages in different geographical regions, which have been documented for P. juxtanucleare in chickens (Valkiūnas 2005). In addition, differences in the virulence of $P$. juxtanucleare towards different hosts are probably due to differences in the innate susceptibility between different hosts. For instance, penguins are known for their high susceptibility to infection by different Plasmodium species (Graczyk et al. 1994, Grim et al. 2003). These birds have poor innate immunity against malaria parasites, presumably because the majority of penguin species spend majority of their life in habitats that usually cannot sustain active malaria transmission (cold environments or the absence of susceptible mosquito vectors, or both).

Some drugs have been successfully administered to treat avian malaria, especially against Plasmodium gallinaceum and P. juxtanucleare (Krettli et al. 2001, Maciel et al. 2008, Vashist et al. 2008, 2009). However, the effective action of the drugs was observed only for the erythrocytic cycle. Moreover, the monitoring period for the birds that received the treatment was not sufficient to observe possible relapses of infection. Chloroquine administration was effective in reducing parasitaemia caused by Plasmodium elongatum and P. relictum in naturally infected penguins (Cranfield et al. 1994). In addition, chickens experimentally infected with $P$. juxtanucleare showed a significant reduction in parasitaemia after chloroquine treatment (Silveira et al. 2009b). A mixture of trimethoprim and sulphaquinoxaline has shown efficacy against $P$. gallinaceum (Williams 2005). Malarone, which is effective against human malaria parasite, $P$. falciparum, was effective against natural and experimental $P$. relictum infections during erythrocytic stages, but was ineffective against tissue stages of this parasite (Palinauskas et al. 2009, Knowles et al. 2010). The methods used to treat avian malaria are not sufficiently developed, presumably because of the low levels of pathogenicity observed during chronic stages of infection in most cases, and an underestimation of the true impact of these parasites have on wildlife, particularly during the acute primary stage of infection.

Concluding remarks - Malaria parasites of the genus Plasmodium are cosmopolitan in distribution and have been reported in birds belonging to many families and orders. The number of publications in this field of parasitology is increasing because malaria parasites and related haemosporidians have recently been recognized as convenient model organisms for evolutionary and conservation biology studies. Molecular methods have provided new opportunities to obtain a more innovative understanding of this fascinating group of pathogens. However, the methods used to diagnose malaria parasites in wildlife need to be developed further. There is an urgent need to combine morphological and rapidly accumulating sequence information, which would facilitate the diagnosis of these parasites, particularly in wildlife. Currently, to obtain true estimates of the diversity and prevalence of malaria parasites, a combination of PCRbased and microscopy-based methods is needed.

Birds are frequently used as ecosystems disturbance indicator and are the most comprehensively studied class of animals. Therefore, parasitism has far-reaching implications, not only for the ecology and evolution of species, but also for the conservation of species. However, few molecular studies on the prevalence and genetic diversity of avian malaria haemoparasites have been conducted in Neotropical regions. Different studies addressing prevalence of avian malaria have been conducted in different regions of Brazil, and markedly different prevalences for Plasmodium spp have been reported. Thus, additional studies are needed to increase our understanding of the diversity, prevalence and distribution patterns of Plasmodium. Such studies will provide additional information on the possible influence malaria has on birds, particularly during anthropogenic disturbances to the environment and natural habitat loss. Such information is essential for future projects aiming to predict and manage the impact of avian malaria on birds.

\section{REFERENCES}

Al-Dabagh MA 1961. Syntomatic partial paralysis in chicks infected with Plasmodium juxtanucleare. J Comp Pathol 71: 217-221.

Applegate JE 1970. Population changes in latent avian malaria infections associated with season and corticosterone treatment. J Parasitol 56: 439-443.

Atkinson CT, Woods KL, Dusek RJ, Sileo LS, Iko WM 1995. Wildlife disease and conservation in Hawaii: pathogenicity of avian malaria (Plasmodium relictum) in experimentally infected Iiwi (Vestiaria coccinea). Parasitology 111 (Suppl.): 59-69.

Beadell JS, Ishtiaq F, Covas R, Melo M, Warren BH, Atkinson CT, Bensch S, Graves GR, Jhala YV, Peirce MA, Rahmani AR, Fonseca DM, Fleischer RC 2006. Global phylogeographic limits of Hawaii's avian malaria. Proc Biol Sci 273: 2935-2944.

Belo NO, Passos LF, Júnior LM, Goulart CE, Sherlock TM, Braga EM 2009. Avian malaria in captive psittacine birds: detection by microscopy and 18S rRNA gene amplification. Prev Vet Med 88: 220-224.

Belo NO, Pinheiro RT, Reis SE, Ricklefs RO, Braga EM 2011. Host species and parasite lineage diversity of haemosporidians in three different environments with distinct levels of disturbance. Plos ONE 6: 17654.

Bennett G, Lopes OS 1980. Blood parasites of some birds from São Paulo state, Brazil. Mem Inst Oswaldo Cruz 75: 117-134.

Bennett GF, Warren M 1966. Biology of the malaysian strain of Plasmodium juxtanucleare Versiani \& Gomes, 1941. 3. Life cycle of the erythrocytic parasite in the avian host. J Parasitol 52: 653-659.

Bensch S, Hellgren O, Pérez-Tris J 2009. MalAvi: a public database of malaria parasites and related haemosporidians in avian hosts based on mitochondrial cytochrome $b$ lineages. Mol Ecol Resour 9: 1353-1358. 
Bensch S, Pérez-Tris J, Waldenström J, Hellgren O 2004. Linkage between nuclear and mitochondrial DNA sequences in avian malaria parasites: multiple cases of cryptic speciation? Evolution 58: 1617-1621.

Bensch S, Stjernman M, Hasselquist D, Ostman O, Hansson B, Westerdahl H, Pinheiro RT 2000. Host specificity in avian blood parasites: a study of Plasmodium and Haemoproteus mitochondrial DNA amplified from birds. Proc Biol Sci 267: 1583-1589.

Bonneaud C, Sepil I, Milá B, Buermann W, Pollinger J, Sehgal RNM, Valkiūnas G, Iezhova TA, Saatchi S, Smith TB 2009. The prevalence of avian Plasmodium is higher in undisturbed tropical forests of Cameroon. J Trop Ecol 25: 439-447.

Bueno MG, Lopez RP, de Menezes RM, Costa-Nascimento M de J, Lima GF, Araújo RA, Guida FJ, Kirchgatter K 2010. Identification of Plasmodium relictum causing mortality in penguins (Spheniscus magellanicus) from São Paulo Zoo, Brazil. Vet Parasitol 173: 123-127.

Chen MM, Shi L, Sullivan Jr DJ 2001. Haemoproteus and Schistosoma synthesize heme polymers similar to Plasmodium hemozoin and beta-hematin. Mol Biochem Parasitol 113: 1-8.

Coatney GR, Collins WE, Warren M, Contacos PG 1971. The primate malarias, US Government Printing Office, Washington, 366 pp.

Cranfield MR, Graczyk TK, Beall FB, Ialeggio DM, Shaw ML, Skjoldager ML 1994. Subclinical avian malaria infections in African black-footed penguins (Spheniscus demersus) and induction of parasite recrudescence. J Wildl Dis 30: 372-376.

Ejiri H, Sato Y, Sawai R, Sasaki E, Matsumoto R, Ueda M, Higa Y, Tsuda Y, Omori S, Murata K, Yukawa M 2009. Prevalence of avian malaria parasite in mosquitoes collected at a zoological garden in Japan. Parasitol Res 105: 629-633.

Elisei C, Souza PCO, Massard CL, Soares CO 2001. Caracterización morfológica y morfometrica de Plasmodium juxtanucleare (Apicomplexa: Plasmodiidae). Parasitol al Dia 25: 1-2.

Fecchio A, Lima MR, Silveira P, Braga EM, Marini MA 2011. High prevalence of blood parasites in social birds from a neotropical savanna in Brazil. Emu - Aust Ornithol 111: 132-138.

Fecchio A, Marini MA, Braga EM 2007. Baixa prevalência de hemoparasitos em aves silvestres no cerrado brasileiro. Neo Biol Conserv 2: 127-135.

Gager AB, Del Rosario Loaiza J, Dearborn DC, Bermingham E 2008. Do mosquitoes filter the access of Plasmodium cytochrome $b$ lineages to an avian host? Mol Ecol 17: 2552-2561.

Galbadon A, Ulloa G 1977. Plasmodium (Haemamoeba) tejerai sp. n. en pavo domestico (Melleagris gallopavo) del Venezuela. Bol Dir Malariol y San Amb 17: 255-273.

Garamszegi LZ 2010. The sensitivity of microscopy and PCR-based detection methods affecting estimates of prevalence of blood parasites in birds. J Parasitol 96: 1197-1203.

Garnham PCC 1966. Malaria parasites and other haemosporidia, Blackwell Scientific Public, Oxford, 1114 pp.

Graczyk TK, Cranfield MR, McCutchan TF, Bicknese EJ 1994. Characteristics of naturally acquired avian malaria infections in naive juvenile African black-footed penguins (Spheniscus demersus). Parasitol Res 80: 634-637.

Grim KC, van der Merwe E, Sullivan M, Parsons N, Mc Cutchan TF, Cranfield M 2003. Plasmodium juxtanucleare associated with mortality in black-footed penguin (Spheniscus demersus) admitted to a rehabilitation center. J Zoo Wildl Med 34: 250-255.

Hellgren O, Križanauskienè A, Valkiūnas G, Bensch S 2007. Diversity and phylogeny of mitochondrial cytochrome $b$ lineages from six morphospecies of avian Haemoproteus (Haemosporida: Haemoproteidae). J Parasitol 93: 889-896.

Hellgren O, Waldenström J, Bensch S 2004. A new PCR assay for simultaneous studies of Leucocytozoon, Plasmodium, and Haemoproteus from avian blood. J Parasitol 90: 797-802.

Iezhova TA, Valkiūnas G, Bairlein F 2005. Vertebrate host specificity of two avian malaria of the subgenus Novyella: Plasmodium nucleophilum and Plasmodium vaughani. J Parasitol 91: 472-475.

Istiaq F, Guillaumot L, Clegg SM, Phillimore AB, Black RA, Owens IP, Mundy NI, Sheldon BC 2008. Avian haematozoan parasites and their associations with mosquitoes across Southwest Pacific Islands. Mol Ecol 17: 4545-4555.

Kim KS, Tsuda Y 2010. Seasonal changes in the feeding pattern of Culex pipiens pallens govern the transmission dynamics of multiple lineages of avian malaria parasites in Japanese wild bird community. Mol Ecol 19: 5545-5554.

Kim KS, Tsuda Y, Sasaki T, Kobayashi M, Hirota Y 2009. Mosquito blood-meal analysis for avian malaria study in wild bird communities: laboratory verification and application to Culex sasai (Diptera: Culicidae) collected in Tokyo, Japan. Parasitol Res 105: 1351-1357.

Kimura M, Darbro JM, Harrington LC 2010. Avian malaria parasites share congeneric mosquito vectors. J Parasitol 96: 144-151.

Knowles SC, Palinauskas V, Sheldon BC 2010. Chronic malaria infections increase family inequalities and reduce parental fitness: experimental evidence from a wild bird population. $J$ Evol Biol 23: 557-569.

Krettli AU 1972. Plasmodium juxtanucleare in the state of Minas Gerais, Brazil. Studies on its prevalence and some aspects of its biology. Rev Inst Med Trop Sao Paulo 14: 235-245.

Krettli AU, Andrade-Neto VF, Brandão MGL, Ferrari WMS 2001. The search for new antimalarial drugs from plants used to treat fever and malaria or plants ramdomly selected: a review. Mem Inst Oswaldo Cruz 96: 1033-1042.

Križanauskiené A, Hellgren O, Kosarev V, Sokolov L, Bensch S, Valkiunas G 2006. Variation in host specificity between species of avian hemosporidian parasites: evidence from parasite morphology and cytochrome $b$ gene sequences. J Parasitol 92: 1319-1324.

Križanauskiené A, Pérez-Tris J, Palinauskas V, Hellgren O, Bensch S, Valkiūnas G 2010. Molecular phylogenetic and morphological analysis of haemosporidian parasites (Haemosporida) in a naturally infected European songbird, the blackcap Sylvia atricapilla, with description of Haemoproteus pallidulus sp. nov. Parasitology 137: 217-227.

Laird M 1998. Avian malaria in the Asian tropical subregion, Springer-Verlag, Singapore, $130 \mathrm{pp}$.

Landau I, Chavatte JM, Peters W, Chabaud A 2010. The sub-genera of avian Plasmodium. Parasite 17: 3-7.

Lefèvre T, Roche B, Poulin R, Hurd H, Renaud F, Thomas F 2008. Exploiting host compensatory responses: the 'must' of manipulation? Trends Parasitol 24: 435-439.

Levin II, Outlaw DC, Vargas HF, Parker PG 2009. Plasmodium blood parasite found in endangered Galapagos penguins (Spheniscus mendiculus). Biol Conserv 142: 3191-3195.

Lima MR, Simpson L, Fecchio A, Kyaw CM 2010. Low prevalence of haemosporidian parasites in the introduced house sparrow (Passer domesticus) in Brazil. Acta Parasitol 55: 297-303.

Loiseau C, Iezhova TA, Valkiūnas G, Chasar A, Hutchinson A, Buermann W, Smith T, Sehgal R N 2010. Spatial variation of haemosporidian parasite infection in African rainforest bird species. J Parasitol 96: 21-29. 
Lourenço-de-Oliveira R, de Castro FA 1991. Culex saltanensis Dyar, 1928: natural vetor of Plasmodium juxtanucleare in Rio de Janeiro, Brazil. Mem Inst Oswaldo Cruz 86: 87-94.

Lucena DT 1939. Malaria aviária: subsídios para sua sistemática e transmissão, PhD Thesis, Jornal do Commércio, Recife, 126 pp.

Maciel C, Junior VXO, Fázio AM, Nacif-Pimenta R, Miranda A, Pimenta PFP, Capurro LM 2008. Anti-Plasmodium activity of angiotensin ii and related synthetic peptides. Plos ONE 3: 3296.

Martínez J, Martínez-De La Puente J, Herrero J, Del Cerro S, Lobato E, Rivero-De Aguilar J, Vásquez RA, Merino S 2009. A restriction site to differentiate Plasmodium and Haemoproteus infections in birds: on the inefficiency of general primers for detection of mixed infections. Parasitology 136: 713-722.

Martinsen ES, Paperna I, Schall JJ 2006. Morphological versus molecular identification of avian Haemosporidia: an exploration of three species concepts. Parasitology 133: 279-288.

Martinsen ES, Perkins S, Schall JJ 2008. A three-genome phylogeny of malaria parasites (Plasmodium and closely related genera): evolution of life-history traits and host switches. Mol Phylogenet Evol 47: 261-273.

Marzal A, Bensch S, Reviriego M, Balbontin J, De Lope F 2008. Effects of malaria double infection in birds: one plus is not two. J Evol Biol 21: 979-987.

Massard CL, Massard CA 1981. Aspectos biológicos do Plasmodium (Novyella) juxtanucleare Versiani e Gomes, $1941 \mathrm{em}$ aves no Brasil. Rev Brasil Med Vet 4: 13-23.

McConkey GA, Li J, Rogers MJ, Seeley DCJR, Grac-Zyk TK, Cranfield MR, McCutchan TF 1996. Parasite diversity in an endemic region for avian malaria and identification of a parasite causing penguin mortality. J Eukaryot Microbiol 43: 393-399.

Møller AP, Nielsen JT 2007. Malaria and risk of predation: a comparative study of birds. Ecology 88: 871-881.

Murata K, Nii R, Sasaki E, Ishikawa S, Sato Y, Sawabe K, Tsuda Y, Matsumoto R, Suda A, Ueda M 2008. Plasmodium (Bennettinia) juxtanucleare infection in a captive white eared-pheasant (Crossoptilon crossoptilon) at a Japanese zoo. J Vet Med Sci 70: 203-205.

Njabo KY, Cornel AJ, Bonneaud C, Toffelmier E, Sehgal RNM, Valkiūnas G, Russell AF, Smith TB 2011. Nonspecific patterns of vector, host and avian malaria parasite associations in a central African rainforest. Mol Ecol 20: 1049-1061.

Palinauskas V, Kosarev V, Shapoval A, Bensch S, Valkiūnas G 2007. Comparison of mitochondrial cytochrome $b$ lineages and morphospecies of two avian malaria parasites of the subgenera Haemamoeba and Giovannolaia (Haemosporida: Plasmodiidae). Zootaxa 1626: 39-50.

Palinauskas V, Valkiūnas G, Bolshakov CV, Bensch S 2008. Plasmodium relictum (lineage P-SGS1): effects on experimentally infected passerine birds. Exp Parasitol 120: 372-380.

Palinauskas V, Valkiūnas G, Bolshakov CV, Bensch S 2011. Plasmodium relictum (lineage SGS1) and Plasmodium ashfordi (lineage GRW2): the effects of the co-infection on experimentally infected passerine birds. Exp Parasitol 127: 527-533.

Palinauskas V, Valkiūnas G, Križanauskienė A, Bensch S, Bolshakov CV 2009. Plasmodium relictum (lineage P-SGS1): further observation of effects on experimentally infected passeriform birds, with remarks on treatment with Malarone ${ }^{\mathrm{TM}}$. Exp Parasitol 123: 134-139.

Paraense WL 2004. A fragment of malaria history. Mem Inst Oswaldo Cruz 99: 439-442.

Pérez-Tris J, Hasselquist D, Hellgren O, Krizanauskiene A, Waldenström J, Bensch S 2005. What are malaria parasites? Trends Parasitol 21: 209-211.
Perkins SL, Schall JJ 2002. A molecular phylogeny of malaria parasites recovered from cytochrome $b$ gene sequences. $J$ Parasitol 88: 972-978.

Ribeiro SF, Sebaio F, Branquinho FCS, Braga EM 2005. Avian malaria in Brazilian passerini birds: parasitism detected by nested PCR using DNA from stained blood smears. Parasitology 3: 261-267.

Richard FA, Sehgal RNM, Jones HI, Smith TB 2002. A comparative analysis of PCR-based detection methods for avian malaria. J Parasitol 88: 819-822.

Ricklefs RE, Fallon SM 2002. Diversification and host switching in avian malaria parasites. Proc R Soc B 269: 885-892.

Ricklefs RE, Fallon SM, Bermingham E 2004. Evolutionary relationships, cospeciation and host switching in avian malaria parasites. Syst Biol 53: 111-119.

Ricklefs RE, Outlaw DC 2010. A molecular clock for malaria parasites. Science 329: 226-229.

Santos-Prezoto HH, D’Agosto M, Daemom E 2004. Prevalência e variação dos estádios eritrocíticos do Plasmodium (Novyella) juxtanucleare em Gallus gallus sob condições naturais, no período de um ano. Parasitol Latinoam 59: 14-20.

Schrenzel MD, Maalouf GA, Keener LL, Gaffney PM 2003. Molecular characterization of malarial parasites in captive passerine birds. J Parasitol 89: 1025-1033.

Sebaio F, Braga EM, Branquinho F, Manica LT, Marini MA 2010. Blood parasites in Brazilian Atlantic Forest birds: effects of fragment size and habitat dependency. Bird Conserv Intern 20: 432-439.

Sehgal RNM 2010. Deforestation and avian infectious diseases. J Exp Biol 213: 955-960.

Sehgal RNM, Buermann W, Harrigan RJ, Bonneaud C, Loiseau C, Chasar A, Sepil L, Valkiūnas G, Iezhova TA, Saatchi S, Smith TB 2011. Spatially explicit predictions of blood parasites in a widely distributed African rainforest bird. Proc R Soc B 278: 1025-1033.

Silveira P, Damatta RA, D'Agosto M 2009a. Hematological changes of chickens experimentally infected with Plasmodium (Bennettinia) juxtanucleare. Vet Parasitol 162: 257-262.

Silveira P, Vashist U, Cabral A, Amaral K B, Soares GLG, D'Agosto M 2009b. Effect of rutin and chloroquine on white Leghorn chickens infected with Plasmodium (Bennettinia) juxtanucleare. Trop Anim Health Prod 41: 1319-1323.

Snow RW, Omumbo JA 2006. Disease and mortality in sub-saharan Africa. In DT Jamison, RG Feachem, MW Makgoba, ER Bos, FK Baingana, KJ Hofman, KO Rogo (eds.), 2nd ed., Malaria World Bank, Washington, p. 195-214.

Tripet F, Aboagye-Antwi F, Hurd H 2008. Ecological immunology of mosquito-malaria interactions. Trends Parasitol 24: 219-227.

Valkiūnas G 1997. Bird Haemosporida, monograph, Institute of Ecology, Vilnius, $607 \mathrm{pp}$.

Valkiūnas G 2005. Avian malaria parasites and other haemosporidia, CRC Press, Boca Raton, Florida, 946 pp.

Valkiūnas G, Anwar AM, Atkinson CT, Greiner EC, Paperna I, Peirce MA 2005. What distinguishes malaria parasites from other pigmented haemosporidians? Trends Parasitol 21: 357-358.

Valkiūnas G, Ashford RW, Bensch S, Killick-Kendrick R, Perkins S 2011. A cautionary note concerning Plasmodium in apes. Trends Parasitol 27: 231-232.

Valkiūnas G, Atkinson CT, Bensch S, Sehgal RN, Ricklefs RE 2008a. Parasite misidentifications in GenBank: how to minimize their number? Trends Parasitol 24: 247-248.

Valkiūnas G, Bensch S, Iezhova TA, Krizanauskienė A, Hellgren O, Bolshakov CV 2006. Nested cytochrome $b$ polymerase chain 
reaction diagnostics underestimate mixed infections of avian blood haemosporidian parasites: microscopy is still essential. J Parasitol 92: 418-422.

Valkiūnas G, Iezhova TA, Križanauskiené A, Palinauskas V, Sehgal RNM, Bensch S 2008b. A comparative analysis of microscopy and PCR-based detection methods for blood parasites. J Parasitol 94: 1395-1401.

Valkiūnas G, Iezhova TA, Loiseau C, Smith TB, Sehgal RNM 2009. New malaria parasites of the subgenus Novyella in African rainforest birds, with remarks on their high prevalence, classification and diagnostics. Parasitol Res 104: 1061-1077.

van Riper III C, Atkinson CT, Seed TM 1994. Plasmodia of birds. In JP Kreier (ed.), Parasitic protozoa, Academic Press, San Diego, p. 73-140.

Vashist U, Carvalhaes R, D'agosto M, Da Silva AD 2009. Antimalarial activity of the novel quinoline/6-thiopurine conjugate in Gallus gallus Linnaeus, infected experimentally by Plasmodium (Novyella) juxtanucleare. Chem Biol Drug Des 74: 434-437.
Vashist U, Silveira P, Cabral A, Amaral KB, Soares GLG, D'Agosto M 2008. Atividade malaricida da quercetina em Gallus gallus L.,1758 imunossuprimidos infectados por Plasmodium (Bennettinia) juxtanucleare Versiani e Gomes, 1941. Rev Bras Parasitol Vet 17: 220-223.

Versiani V, Gomes BF 1941. Sobre um novo hematozoário de galinha, Plasmodium juxtanucleare n. sp. (nota prévia). Rev Bras Biol 1: 231-233.

Waldenström J, Bensch S, Hasselquist D, Ostman O 2004. A new nested polymerase chain reaction method very efficient in detecting Plasmodium and Haemoproteus infections from avian blood. J Parasitol 90: 191-194.

Williams RB 2005. The efficacy of a mixture of trimethoprim and sulphaquinoxaline against Plasmodium gallinaceum malaria in the domesticated fowl Gallus gallus. Vet Parasitol 129: 193-207.

Woodworth-Lynas CB, Caines JR, Bennett GF 1989. Prevalence of avian Haematozoa in São Paulo state, Brazil. Mem Inst Oswaldo Cruz 84: 515-526. 